\title{
Incidencia del concepto de previsión en los elementos de la responsabilidad civil en Colombia*
}

\section{Lorena Piedad Campos Cuesta*}

Resumen. En la actualidad, para la sociedad moderna resulta cada vez más importante optar por conductas encaminadas a evitar la ocurrencia de daños, realidad que no ha sido ajena al derecho en general, y al de daños en especial, y que ha llevado a que cada día tomen más relevancia las posturas encaminadas hacia la prevención y mitigación de los daños. Así, previsibilidad, previsión e imprevisión son conceptos que han sido empleados en los juicios de responsabilidad como manifestaciones tradicionales de anticipación y factores determinantes en el límite entre la atribución de responsabilidad y su liberación.

Palabras clave: previsibilidad, imprevisibilidad, responsabilidad.

Fecha de recepción: 17 de julio de 20I7. Fecha de aceptación: 30 de abril de 2018.

Para citar el artículo: Campos Cuesta, L. P., "Incidencia del concepto de previsión en los elementos de la responsabilidad civil en Colombia", Revista de Derecho Privado, Universidad Externado de Colombia, n. ${ }^{\circ}$ 35, julio-diciembre de 2018, 245-259. Dor: https://doi. org/I0.1860I/or 234366.n35.09

Este artículo corresponde a una adaptación de la tesis de grado de maestría en Derecho con énfasis en Responsabilidad Contractual y Extracontractual Civil y del Estado, 20 I I-20 I 2, dirigida por Édgar Cortés Moncayo.

** Abogada. Magíster en Responsabilidad Contractual y Extracontractual Civil y del Estado, Universidad Externado de Colombia, con experiencia en el sector público y privado en asuntos de responsabilidad, seguros, contratos y conflictividad social. Contacto: lorenacampos.cuesta@ gmail.com 


\title{
The Concept of Predictability in the Elements of Civil Liability in Colombia
}

\begin{abstract}
Nowadays, for modern society, it is becoming increasingly important to opt for behaviors aimed at preventing the occurrence of damages, a reality that has not been separate to the law in general, and that of damages in particular, and that has led taking of more relevance the positions aimed at the prevention and mitigation of damages. Thus, the concepts of forecasting, predictability, and unpredictability, have been used in liability judgments as traditional indications of anticipation, as well as determining factors of the borderline between the attribution of liability or its release.
\end{abstract}

Keywords: Predictability, unpredictability, responsibility.

Sumario. Introducción. I. Precisiones respecto de la previsión en el daño: la tipología de daño previsible e imprevisible en la responsabilidad. Ir. La previsibilidad como elemento estructural de la diligencia. III. La imprevisibilidad, un factor determinante para la configuración de las causales de exoneración: incidencia y valoración del acontecimiento imprevisible. Conclusión. Referencias.

\section{Introducción}

La previsión, la previsibilidad y la imprevisibilidad, en el lenguaje común, definen una conducta dirigida a la anticipación o no de contingencias futuras pero normales que pueden llegar a suceder, lo que inhibe una conducta acompañada de ciertas circunstancias ${ }^{\mathrm{I}}$, concepto que no dista del empleado en materia de responsabilidad. Así, verbigracia, Cornu precisa la noción de previsibilidad como aquello que tiene carácter de previsible ${ }^{2}$, antónimo de imprevisibilidad, y define lo previsible como lo que normalmente se puede esperar y que, por tanto, puede preverse razonablemente; término empleado en el daño, el evento o suceso y en el riesgo. Lo menciona como sinónimo de probable, posible, y a propósito de la fuerza mayor 3 ; el Diccionario de derecho usual define la previsibilidad como parte

I La "previsión" es señalada por la Real Academia de la Lengua Española como derivada del latín praevisio, y definida como referida a la "acción y efecto de prever", siendo "la acción de disponer lo conveniente para atender a contingencias o necesidades previsibles". El verbo "prever" proviene del latín praevidère, que se entiende como: "Ver con anticipación, 2.tr. Conocer, conjeturar por algunas señales o indicios lo que ha de suceder, 3.tr. Disponer o preparar medios contra futuras contingencias". Y precisando lo previsible como aquello que "puede ser previsto o entra dentro de las previsiones normales". Entiende la Real Academia que la imprevisibilidad es la "cualidad de imprevisible", esto es, que "no se puede prever". Cfr.: http://lema.rae.es/ drae/?val=previsi\% $\mathrm{C}_{3} \% \mathrm{~B}_{3} \mathrm{n}$ [consultada el ig de noviembre de 20 2 ].

2 Connu, G., Vocabulaire juridique, Association Henri Capitant, 8. ${ }^{2}$ ed., 2000, 670.

3 Ibíd., 392. 
estructural de la culpa 4 ; a su vez, el Diccionario español jurídico 5 establece distinción en la definición misma, entre la previsibilidad subjetiva y la objetiva, referida la primera a culpabilidad, error de tipo e imprudencia, mientras la segunda a la imputación objetiva, aunque ambas confluyen igualmente en la imprudencia.

Este concepto de previsión es similar a la noción traída del léxico común ${ }^{6}$, pues no se diferencia de lo que entiende el lego; sin embargo, para el derecho el término es utilizado en escenarios precisos, y es objeto de apreciaciones que no son tenidas en cuenta en cualquier otra ciencia de estudio.

Por lo dicho, resulta que el concepto de previsión empleado en la responsabilidad puede entenderse como "la conducta dirigida a anticiparse a los daños que pueden provenir de un comportamiento o de un hecho, frente a contingencias futuras pero normales que han debido ser advertidas", para con ello entrar a determinar si su comportamiento tiene o no incidencia alguna en el juicio propio, con importancia tal que comprometa su responsabilidad, en caso de serle previsible, o no, en el evento en que esta le sea imprevisible, por constituir con ello un elemento de las causales de exoneración.

Esta anticipación referida no es asimilable a la conducta profética que se exige de los adivinos, pues no debe perderse de vista el carácter objetivo, normativo y propio que ha construido la teoría jurídica para mantenerse al margen de condiciones psíquicas pertenecientes por demás a otras ciencias. Valga advertir que la conducta del deudor de anticiparse no es equiparable a la reproducción mental que debe hacer de todas y cada una de las posibles causas de daños, sino a la comprobación de aquellas que debieron ser advertidas en atención a su posición frente a factores subjetivos y objetivos de referencia.

La previsión es ubicada en los tres elementos tradicionales determinantes de la responsabilidad, teniendo con ello gran incidencia en los juicios en los que se pretende la reparación de los daños causados; empleada como soporte para la creación de una categoría independiente de daño, previsible e imprevisible, como elemento de la diligencia, y como factor en las causales de exoneración de responsabilidad. Pese a ello, ha sido tratada de forma indiferente por el jurista, quien en muchos de los eventos, inclusive, ha limitado su presencia a la fuerza mayor y el caso fortuito, para terminar por descartarla por su inoperancia en la práctica; sin embargo, la existencia de la previsión en la responsabilidad parece no ser tan simple.

4 Diccionario de Derecho Usual, 4. ${ }^{\mathrm{a}}$ ed., t. III, Buenos Aires, Omeba, 1962.

5 Diccionario Español furídico, disponible en: http//: http://dej.rae.es/\#/entry-id/Er 89930 y http:// dej.rae.es/\#/entry-id/Eı 89920 [consultado el i9 de febrero de 2018].

6 Lecuyer, H., "El contrato: acto de previsión”, en Revista de Derecho Privado, Universidad Externado de Colombia, n. ${ }^{\circ}$ I 8, 2010, 39 . 


\section{Precisiones respecto de la previsión en el daño: la tipología de daño previsible e imprevisible en la responsabilidad}

A propósito de la aplicación del concepto de previsión en el daño, como fuente de la obligación de reparar y primer elemento de la responsabilidad, se tiene que la incidencia del concepto de previsión ha venido a ser abordado a través de la estructuración de los daños merecedores de tutela, por lo que alguna parte de la doctrina y la jurisprudencia considera que dentro de la tipología del daño ha de considerarse el daño previsto y el daño imprevisto ${ }^{7}$.

En relación con el papel de la previsión en torno al daño en la responsabilidad civil contractual, el código civil francés de I804 menciona en su artículo I I 50 : "El deudor no solo está obligado por daños y perjuicios que hayan sido previstos o que se hayan podido prever al hacerse el contrato, cuando no se deba a su dolo el que la obligación se incumpla”. Según lo ordenado por el código civil francés, los Mazeaud encontraron el soporte del llamado daño previsible, entendiéndolo como una regla de limitación en la reparación del daño, en el sentido de que solo se repara aquel que es previsible al deudor de una culpa contractual no intencional en el momento de celebrar el contrato ${ }^{8}$; artículo este criticado frecuentemente, "pero a veces también defendido brillantemente"9.

El artículo r6 6 c.c. colombiano dispone: "Si no se puede imputar dolo al deudor, solo es responsable de los perjuicios que se previeron o pudieron preverse al tiempo del contrato; pero si hay dolo, es responsable de todos los perjuicios que fueron consecuencia inmediata o directa de no haberse cumplido la obligación o de haberse demorado su cumplimiento", que hace mención a la responsabilidad del deudor doloso por los considerados "perjuicios previsibles e imprevisibles" en el momento de la celebración del contrato; al respecto, la Corte Suprema de Justicia, en sentencia de 29 de octubre de I 945 , menciona que los perjuicios contractuales a los que se refiere el mencionado artículo i 6 I 6 pueden ser directos, y estos a su vez se clasifican en previstos e imprevistos en el momento de

7 Bustamante Alsina precisa que el daño se divide en previsto e imprevisto: previsible o no, siendo los primeros aquellos que "el deudor o el autor del acto ha considerado posibles al contraer la obligación o ejecutar el acto", y los segundos "los que no han sido considerados"; lo anterior al analizar la actuación del sujeto en abstracto, en relación con la previsibilidad media, esto es, de una persona que actúe con la debida atención y conocimiento de la cosa. Esta clasificación tiene sustento en la afirmación según la cual lo previsible es lo que se puede prever y lo imprevisible lo que no, derivado del análisis que se hace del artículo 904 c.c. argentino, que a su vez refiere lo que denominó daños inmediatos, mediatos y causales, en donde "[l]os daños inmediatos son de previsibilidad presumida por la ley dada la forma en que suceden; los mediatos son de previsibilidad posible; los causales son imposibles de prever”. Bustamante Alsina, J., Teoría general

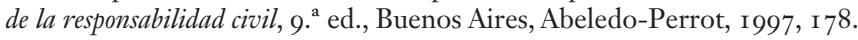

8 Mazeaud, H. y L., Tratado teórico y práctico de la responsabilidad civil delictual y contractual, t. II, vol. II, trad. de la 5. ${ }^{\text {a }}$ ed., L. Alcalá Zamora y Castillo, Buenos Aires, EJEA, I963, 568, 569, 573.

9 Souleau, "La prévisibilité du dommage contractuel (Défense et illustration de l'article i I 50 du Code civil)”, Paris II, I979, cit. por LeCuyer, El contrato: acto de previsión, cit., 49. 
celebrar el contrato, considerando los primeros como aquellos "que se previeron o que pudieron ser previstos al tiempo de celebrarse el contrato, y los segundos aquellos que las partes no han previsto o no han podido prever en ese mismo momento”. Con esto, al crear una tipología propia, que no estaba determinada en la norma, empleó un juego de palabras que generó confusión al intérprete que buscaba darle aplicación, prefiriendo, en muchas de las oportunidades, dejarla de lado y con ello evitar su enredada implementación.

De acuerdo con la norma citada, la Corte Constitucional colombiana, en sentencia C-ıoo8 de 20ıо, le otorgó relevancia jurídica al contenido lingüístico de la previsión, al entenderla como "la posibilidad que tiene un deudor diligente de haberlo [sic] contemplado anticipadamente el efecto del incumplimiento de lo pactado en el contrato"

Esta denominada 'clasificación', más que una categorización parece ser una reticencia de lo que se ha establecido como sentido de la regla, pues al afirmar que los perjuicios son previsibles porque se previeron o pudieron preverse al tiempo del contrato hace referencia es a la previsión como elemento de la diligencia propia de la culpa, lo que, como se verá, no la hace una categoría distinta de perjuicio, sino la ratificación del elemento subjetivo en la responsabilidad contractual, de manera que, si no se puede imputar dolo al deudor contractual, sí se hará por culpa, de encontrarse esta demostrada.

En este sentido, y al mencionar el artículo r6 6 c.c., los perjuicios que fueron consecuencia inmediata o directa de no haberse cumplido la obligación o de baberse demorado su cumplimiento, es decir, los ocasionados por dolo del deudor, no parece tratarse de un perjuicio independiente merecedor de tutela, sino que representa la exigencia en el juicio de reproche al deudor malicioso, frente al cual la gravedad de su conducta no amerita más precisiones ni reparos; por lo que, comprobada la intención perniciosa, ordena reparar los perjuicios que sean consecuencia inmediata o directa del incumplimiento total o tardío; es decir, manda, como siguiente paso, hacer el análisis de imputación de responsabilidad. Es por esto que el deudor doloso podría exonerarse de responsabilidad si se comprueba que su conducta no fue la causa adecuada del daño, pues en este sentido la norma lo aclaró al hacer la precisión.

Así, desde el punto de vista del concepto de previsión, cuando se hace referencia a la imprevisibilidad en la interpretación del artículo i6 I6 c.c. por la jurisprudencia, al parecer se estaría tratando de la imputación, pues la norma hace alusión expresa es a la consecuencia inmediata o directa, análisis que se realiza en la imputación del daño ${ }^{11}$. En consonancia con ello, la función que cumple

Io Corte Constitucional. Sentencia C-1008 de 2010, M.P.: Luis Ernesto Vargas Silva.

I I En igual medida se ha rechazado la incorporación del carácter directo en el daño por considerar que es un asunto que se estudia a propósito de la imputación. En este sentido, el Henao Pérez afirma, siguiendo a Michel Rougevin-Baville (La responsabilité administrative, Paris, Hachette, 
la causalidad en la responsabilidad, para Díez-Picazo, es de atribución de una consecuencia, y de alcance del daño en su vínculo con la persona, que comporta

... encontrar alguna razón por la cual el daño pueda ligarse con una determinada persona, de manera que se pongan a cargo de ésta, haciéndola responsable, las consecuencias indemnizatorias, para lo cual utiliza el concepto de causa [...] al imponer el deber de indemnizar a 'el que causa daño a otro'; en segundo lugar, se trata de relacionar, a la inversa de lo que hacíamos anteriormente, al daño con la persona, pues el precepto, remarcando el uso de la palabra causa, dice que se indemniza 'el daño causado' ${ }^{\mathrm{I} 2}$.

Sin que esto implique que sea un elemento del daño.

$\mathrm{Al}$ no contener la clasificación de daños previsibles e imprevisibles elementos diferenciadores y propios, podría no constituir una tipología independiente, sino, por el contrario, la reiteración del carácter subjetivo de la responsabilidad y la gravedad del juicio de reproche en contra del deudor doloso.

\section{La previsibilidad como elemento estructural de la diligencia}

En los regímenes de responsabilidad ocupa un lugar relevante el análisis del comportamiento humano ${ }^{13}$, realizado -generalmente- a propósito de la culpa, en sus distintas manifestaciones ${ }^{\mathrm{I}}$. Del vínculo entre la previsión y la noción de culpa dan cuenta De Cupis ${ }^{15}$ y Mosset Iturraspe, según los cuales deriva del pasaje del Digesto D. 9.2.3I: "culpam autem esse, quod cum a diligente provideri poterit, non esset provisum aut tum denuntiatum esset, cum periculum evitari non possit (hay culpa porque no se previó aquello que con diligencia hubiera debido preverse)" ".6. Mención que en un principio dio origen al sustento del concepto de previsión como parte de la concepción psicológica de culpa ${ }^{17}$, derivado de un deber de diligencia del deudor de la obligación de reparar aquellos perjuicios

I992, I39), que se excluye del daño la característica de directo porque "plantea en realidad un problema de imputación”. Henao, J. C., El daño, Bogotá, Universidad Externado de Colombia, I998, 87 .

i Díez-Picazo, L., Derecho de daños, Madrid, Civitas, i 999, 33 I.

I 3 Tamayo Jaramillo, J., Tratado de responsabilidad civil, t. I, 5. ${ }^{\text {a }}$ impr., Bogotá, Legis, 2 o Io, i 88.

I4 Viney menciona que un mismo comportamiento puede ser calificado por un juez de "culpa contractual" cuando se ha perjudicado al contratante, y de "culpa delictual" cuando esta ha afectado a terceros. Viney, G., Tratado de derecho civil. Introducción a la responsabilidad, trad. F. Montoya Mateus, Bogotá, Universidad Externado de Colombia, 2007, 338.

i 5 De Cupis, A., El daño, trad. de la 2. a ed., A. Martínez Sarrión, Barcelona, Bosch, I975, I87.

i6 Mosset Iturraspe, J., Responsabilidad por daños, vol. I, "Parte general”, t. I, Buenos Aires, Ediar, I97I, 60, 6I y 7I.

I 7 Sarmiento, M. G., Estudios de responsabilidad civil, 2. a ed., Bogotá, Universidad Externado de Colombia, 2009, 343 . 
que hubiesen podido y debido preverse, o cuando a pesar de haberlos previsto, confió imprudentemente en poder evitarlos ${ }^{18}$, justificado en un estado anímico que resultaba reprobado y en el que solían encontrarse los individuos dispuestos a evitar los daños ${ }^{19}$. Por lo dicho, el concepto de previsibilidad se encontraba ligado a la culpa, como uno de los elementos que la componían.

Dado lo anterior, al deudor de la obligación de reparar le bastaba representarse las circunstancias imaginables tanto y en cuanto su mente alcanzara a visualizarlas. Por tanto, por cuenta de la sujeción a la mente del deudor y a su capacidad de recrear todos y cada uno de los posibles resultados que podrían presentarse, fue criticada la previsión como elemento de la diligencia; igualmente al considerarse que con las palabras en que se había descrito, la previsión incluía situaciones que nada tenían que ver con la culpa, pues existían casos en los que el deudor sería responsable "aun cuando al momento de obligarse hubiere tomado todas las previsiones humanamente posibles para cumplir” ${ }^{20}$, relegándolo a un elemento diferenciador secundario derivado de la impericia, al definirla como "la temeridad o ligereza con que el sujeto realiza una conducta, bien sea porque no prevea los efectos de la misma, debiéndolos prever, o porque a pesar de haberlos previsto se confía en poderlos evitar"; entonces, la suerte que siguió la culpa en apariencia la tuvo la previsibilidad, tal como una parte sigue a su todo.

Esta sujeción entre la previsión y la noción psicológica de culpa contractual, y las críticas imperantes, hicieron que se considerara la inclusión de elementos externos que dieran precisión a lo que debía serle exigido al deudor de la obligación de reparar; por esto, se hizo imperante atender a las circunstancias externas que rodearon el caso concreto, respecto de las cuales la intención psíquica del agente no representará un papel determinante en la valoración de la conducta, como una forma de dotarla de elementos objetivos que le permitieran al intérprete determinar si el suceso era esperado o no por el deudor; como lo menciona Cortés: "el culpable puede haber actuado de buena fe desde el punto de vista subjetivo, pero en su utilización concreta, el criterio de culpa exige una valoración que se hace según criterios objetivos" ${ }^{2}$. Esta realidad hizo que la conducta debiera ser valorada de manera particular conforme a parámetros objetivos de referencia, dándole un contexto más externo, teniendo en cuenta los acontecimientos que rodeaban el comportamiento del agente en el momento de la valoración de su conducta; esto es, atendiendo a las circunstancias de tiempo, modo y lugar en las que este se despliega, el entorno fáctico y su influencia en la conducta humana.

SARMiento, ob. cit., 343 .

Tamayo Jaramillo, ob. cit., 406.

Cortés, É., La culpa contractual en el sistema jurídico latinoamericano, 2. a ed., Bogotá, Universidad Externado de Colombia, 2009, I 23 
Por lo anterior, la previsión, como elemento de la diligencia, aparentemente fue dejada de lado en el camino por entenderla eminentemente subjetiva, gracias al vínculo atribuido con la culpa psicológica; sin embargo, a pesar de la declinación de esta, puede decirse que la previsión se mantuvo, pero ya destinada a la valoración del comportamiento, de manera que anticipar no hacía ya referencia a la representación mental del daño sino a la conducta desplegada a propósito del evento cuya responsabilidad se analizaba, esto es, al comportamiento previsible. En relación con la vigencia del comportamiento previsible, Bianca afirma: "El juicio de diligencia asume como contenido el comportamiento de sus concretas circunstancias; se valoran en particular los impedimentos que pueden presentar estas circunstancias y que se deben tender a superar mediante el esfuerzo diligente" ${ }^{22}$; y respecto de la apreciación objetiva de la previsibilidad señala: "es realmente fácil percatarse de que todos los impedimentos sobrevenidos, externos e internos, se resuelven, en definitiva, en obstáculos al comportamiento, que son susceptibles de la misma apreciación objetiva de previsibilidad y superabilidad"23. Así, la previsión superó las consideraciones eminentemente subjetivas y fue ligada al comportamiento, como la capacidad del deudor de anticiparse al evento dañino, fácilmente verificable a través de los variopintos medios probatorios externos que determinarían, ya en esta fase, la relevancia de la actividad desplegada por el deudor de la obligación de reparar.

La previsión, como elemento de la diligencia, a la luz de la prevención de los daños permite exigir de parte del deudor la anticipación de las contingencias futuras que debieron ser advertidas; verbigracia, atendiendo a los análisis de riesgos, una compañía del mercado de valores anticipa la caída de un sistema numérico que ocasionará grandes pérdidas, por lo que decide conservar la mayoría de sus acciones en beneficio de sus clientes, haciendo a largo plazo que, llegado el momento previsto, las acciones pierdan el poder adquisitivo y por ende menoscaben en el patrimonio de los accionistas ${ }^{24}$. En un juicio de responsabilidad de un caso así, el análisis de la conducta debe dirigirse en un primer momento al comportamiento desplegado, que aquí consistió en haber anticipado el daño y decidir conservar las acciones, siendo esperable que en el término previsto estas no tuvieran el mismo valor adquisitivo de conformidad con el movimiento

22 Bianca, C. M.; Alpa, G.; Corsaro, L.; Fernández Cruz, G.; Franzoni, M. P.; Monateri, G.; Salvi, C. y Schlesinger, P., Estudios sobre la responsabilidad civil, trad. y ed. L. L. León, 200 , Lima, Ara, 347.

23 Ibíd., 349.

24 El ejemplo es tomado de la película Margin Call (El precio de la codicia), del director J. C. Chandor, que describe la situación que se vive en un banco en Estados Unidos durante las 24 horas previas al inicio de la crisis financiera de 2008 . Luego de realizado un análisis de riesgos por parte de un técnico, encuentran los directivos que es inminente la crisis del sistema financiero, por lo que deciden vender sus acciones a precio actual a sabiendas de que en pocas horas perderán todo su valor en el mercado. 
normal y fluido del mercado. Luego, esta conducta previsible, comparada con aquella desplegada por el común de las personas, arrojaría que una persona común puesta en las mismas circunstancias hubiera vendido, esperando un tercer momento, esto es, la condición de inminente caída del sistema.

Respecto de la valoración de la previsión como elemento de la diligencia, se tiene que, en la medida que lo que reviste de importancia en la valoración jurídica es el comportamiento humano, que provoca un cambio en la situación jurídica existente, esto es, el comportamiento previsible debe ser abordado como un acto jurídico, tal y como lo menciona Hinestrosa ${ }^{25}$ y lo precisa Betti ${ }^{26}$. Es así como, entendida la valoración de la previsibilidad en la conducta como acto jurídico ${ }^{27}, \mathrm{y}$ realizada conforme a parámetros objetivos y subjetivos de referencia, el evaluador podría determinar, junto a los otros elementos, si la conducta fue o no diligente.

\section{La imprevisibilidad, un factor determinante para la configuración de las causales de exoneración: incidencia y valoración del acontecimiento imprevisible}

Para la legislación y la jurisprudencia nacional es claro que la imprevisibilidad es un elemento estructural de las causales de exoneración. Aunque en un inicio el estudio se centró en su influencia en la fuerza mayor y el caso fortuito, este posteriormente se hizo extensivo a los demás eximentes de responsabilidad, ampliando su campo de aplicación, y unido a los otros elementos estructurales, irresistibilidad y exterioridad respecto del demandado ${ }^{28}$.

El contenido del concepto de imprevisibilidad como elemento de la causa extraña, ha sido objeto de diferentes pronunciamientos jurisprudenciales que lo han entendido de forma diversa. Por un lado, como un concepto prevalentemente jurídico, antes que gramatical, en virtud del cual sobreviene un acontecimiento calificado como súbito, sorpresivo o excepcional, que acaece con independencia del actuar diligente del deudor ${ }^{29}$; se considera entonces la imprevisibilidad como

25 Hinestrosa, F., Conferencias de obligaciones, Bogotá, Universidad Externado de Colombia, I955, I 2.

26 Betтr. E., Teoría general del negocio jurídico, 2. ${ }^{\mathrm{a}}$ ed., trad. y concordancias con el derecho español por A. Martín Pérez, Madrid, Revista de Derecho Privado, I959, I3.

27 Alessandri Rodríguez, A. y Somarriva Undurraga, M., Curso de derecho civil. Basado en las explicaciones de los profesores de la Universidad de Chile, redactado y puesto al día por Antoni Vodanovic H., t. I, Santiago de Chile, Nascimento, i 939, 349, 350. Cariota Ferrara, L., El negocio jurídico, trad., prólogo y notas de M. Albaladejo, Madrid, Aguilar, I 956, 6.

28 Consejo de Estado, Sala de lo Contencioso Administrativo, Sección Tercera. Sentencia del i 9 de agosto de 1994, C.P.: Daniel Suárez Hernández, rad.: 9.276. Reiterada en Consejo de Estado, Sala de lo Contencioso Administrativo, Sección Tercera. Sentencia del 26 de marzo de 2008, exp.: i6.530, C.P.: Mauricio Fajardo Gómez.

29 En idéntico sentido, Corte Suprema de Justicia, Sala Civil. Sentencia de 27 de febrero 2009, ref. 733 I9-3103-002-200 I-000 I 3-O I, M.P.: Arturo Solarte Rodríguez. Reiteración de la sentencia del 23 de junio de 2000 , exp. 5475 . 
"aquella circunstancia respecto de la cual 'no sea posible contemplar por anticipado su ocurrencia' $3 \circ$, toda vez que ' $[\mathrm{P}]$ rever, en el lenguaje usual, significa ver con anticipación'" 3 I. Por otro lado, se entiende el concepto de imprevisibilidad en un sentido gramatical para darle solución al caso concreto: "[1]a imprevisibilidad que determina la figura, se presenta cuando no es posible contemplar el hecho con anterioridad a su ocurrencia" ${ }^{2}$.

Por lo dicho, en lugar de proceder a la creación de un concepto de imprevisión con contenido jurídico por vía jurisprudencial, los altos tribunales han empleado el significado dado en el lenguaje común, esto es, no anticipar, pero otorgándole una valoración a lo imprevisible como el evento o acontecimiento sorpresivo, súbito, excepcional o de rara ocurrencia, refiriéndose a los hechos como eje central del estudio en sede de las causales de exoneración, y por ende de la imputación del daño orientado a los acontecimientos en los que se desarrolla la conducta del autor en el momento en que se ocasiona el daño; esto es, a los hechos que rodearon su ocurrencia, los que, una vez identificados, pasarán a ser sometidos al juicio de estimación para determinar si fueron o no excepcionales.

En el esfuerzo realizado por la jurisprudencia colombiana por mantener la imprevisibilidad en el ordenamiento con soporte en el artículo 64 c.c., reformado por el artículo i. ${ }^{\circ}$ de la Ley 95 de I 890 , le ha otorgado continuidad y validez en la valoración de la imprevisibilidad en un sentido diferente a las condiciones síquicas del deudor; así, la jurisprudencia reconoció que la imprevisibilidad cuenta con tres criterios sustanciales que deben ser tenidos en cuenta cuando de establecer el juicio de responsabilidad se trata, a fin de obviar todo tipo de generalización y limitarse el análisis al caso concreto; son ellos: "I) El referente a su normalidad y frecuencia; 2) El atinente a la probabilidad de su realización, y 3) El concerniente a su carácter inapropiado, excepcional y sorpresivo" 33 . Esto como una forma de superar posturas anteriores respecto de la valoración de lo imprevisible otorgándole a la anticipación un contenido externo, objetivo, verosímil y actual.

Los acontecimientos imprevisibles, valorados como hechos jurídicos relevantes para el derecho, presentes en los juicios de responsabilidad calificados como sorpresivos, súbitos, excepcionales o de rara ocurrencia en atención a los

30 Corte Suprema de Justicia, Sala Civil. Sentencia del 20 noviembre de I989, en furisprudencia y Doctrina, Legis, t. xIx, 8, citada en Consejo de Estado, Sala de lo Contencioso Administrativo, Sección Tercera. Sentencia del 26 de marzo de 2008, exp. 6530, C.P.: Mauricio Fajardo Gómez.

3 I Corte Suprema de Justicia, Sala Civil. Sentencia del 26 mayo de I936, xLIII, 58 I. Citada en Consejo de Estado, Sala de lo Contencioso Administrativo, Sección Tercera. Sentencia del 26 de marzo de 2008, exp. 6530, C.P.: Mauricio Fajardo Gómez.

32 Consejo de Estado, Sala de lo Contencioso Administrativo, Sección Tercera. Sentencia del i I de septiembre de 2003 , exp. I4.78 I, C.P.: Ricardo Hoyos Duque.

33 Corte Suprema de Justicia, Sala Civil. Sentencia 23 de junio de 200o, exp. 5.475, M.P.: Carlos Ignacio Jaramillo Jaramillo. 
criterios dados por la jurisprudencia de normalidad y frecuencia, probabilidad de su realización, y su carácter inapropiado, excepcional y sorpresivo, traerán como consecuencia la declaratoria de responsabilidad o la liberación del obligado. Así, verbigracia, respecto de los eventos de la naturaleza considerados como hechos jurídicos constitutivos de exoneración de responsabilidad, habrá de determinarse en cada caso qué debe entenderse por excepcional, y con ello darle el tratamiento jurídico que le corresponda, pues a pesar del avance de la ciencia moderna habrá eventos en los que la naturaleza se manifieste de forma sorpresiva, situaciones en las cuales necesariamente habría que hacer un análisis de imprevisibilidad del fenómeno.

A propósito de las consideraciones de la jurisprudencia nacional en relación con la valoración del acontecimiento imprevisible ${ }^{34}$, es de aclarar que el análisis de atribución corresponde hacerlo al juez al conocer del proceso de responsabilidad, pero respecto de las circunstancias propias que rodearon los sucesos en el momento del daño que se endilga, pues de otra forma se estaría juzgando de forma incorrecta. Entonces, deberá estudiarse el caso concreto a la luz de los hechos, haciendo con esto un análisis en prospectiva, que dependerá de las circunstancias de tiempo, modo y lugar en que se presente el daño, lo que hace de la imprevisibilidad un concepto relativo a las condiciones en las que acaezca ${ }^{35}$. Verbigracia, mientras se espera el paso cerca de la Tierra de un asteroide que finalmente sigue su curso y no ingresa a la órbita terrestre, al mismo tiempo entra a la atmósfera un meteorito que de forma inesperada causa a su paso graves y cuantiosos daños ${ }^{36}$; aunque en sede de la imprevisibilidad por eventos de la naturaleza suelen 'casi todos' los hechos ser anticipados, esto es, son previsibles, ello no implica que sea siempre así, pues al ser humano, aun con el avance de la ciencia, se le presentan circunstancias que pueden no ser conocidas de antemano.

La actualidad y necesidad de la imprevisibilidad como elemento de las causales de exoneración no ha se ha reconocido de forma pacífica. Entre sus detractores, Peirano Facio 37 sostuvo que desde el punto de vista teórico podría no incluirse la imprevisibilidad entre los caracteres del caso fortuito, por considerar que ensanchando el concepto de irresistibilidad se incluirían situaciones que no constituirían verdaderos casos fortuitos, aunque prefirió conservarlo, pero reservándole a la noción un sentido más restringido. A su turno, para Tamayo

34 Consejo de Estado, Sala de lo Contencioso Administrativo, Sección Tercera. Sentencia del 9 de junio de 2005, exp. I 4.392: "la irresistibilidad y la imprevisibilidad del fenómeno definen su configuración, exigencias a las cuales se debe agregar el hecho de que éste no resulte imputable a una de las partes del contrato, aspectos que se deben analizar en cada caso concreto".

35 Consejo de Estado, Sala de lo Contencioso Administrativo, Sección Tercera, Subsección A. Sentencia del 9 de febrero de 20 I r exp. 19.462. Cfr., en el mismo sentido, Consejo de Estado, Sala de lo Contencioso Administrativo, Sección Tercera. Sentencia del 22 de julio de 2009.

36 El ejemplo referido es tomado de un fenómeno natural ocurrido en el año 2013 en Rusia.

37 Peirano Facio, J., Responsabilidad extracontractual, Buenos Aires, Depalma, I954, 468, 469 ss. 
Jaramillo "lo imaginable o lo inimaginable con anticipación conduce siempre a la búsqueda de la irresistibilidad, o por lo menos, de la culpabilidad del agente para lograr resistir el hecho", por lo que propone entender lo imprevisible como aquello "cuya ocurrencia, pese a la diligencia y cuidado del agente, es inevitable" ${ }^{8}$. Y Paillet agregó que la imprevisibilidad no tiene un papel independiente de la irresistibilidad: "la imprevisibilidad viene a juntarse a la irresistibilidad en cuanto aquello que es previsible no es normalmente irresistible [...] de suerte que la imprevisibilidad es un instrumento de medida bastante aproximativo que completa la irresistibilidad sin tener un papel autónomo absolutamente incontestable en términos absolutos o en todo caso constante" 39.

En defensa de la imprevisibilidad como elemento autónomo e independiente, los Mazeaud afirmaron que, si bien "es preferible conservarle a cada expresión un sentido más restringido", "[l]a imposibilidad existe desde el instante en que el cumplimiento no ha podido tener lugar: el concepto de irresistibilidad o imposibilidad se detiene ante la comprobación del hecho, sin averiguar la causa del mismo. Así, los dos caracteres son muy distintos. Puede haber irresistibilidad sin imprevisibilidad"4․ Posición que ha sido acogida por la Corte Suprema de Justicia de Colombia en sentencia de 23 de junio 2000 , al considerar que nuestro derecho consagra los dos presupuestos, la imprevisibilidad y la irresistibilidad del acontecimiento, definidos en la ley positiva ${ }^{4 \mathrm{I}}$; esto es, en el artículo 64 c.c., reformado por el artículo i de la Ley 95 de i89o, que define la imprevisibilidad como elemento de las causales de exoneración en general y del casus de fuerza mayor y fortuito, en especial; la disposición normativa señala: "se llama fuerza mayor o caso fortuito, el imprevisto a que no es posible resistir, como un naufragio, un terremoto, el apresamiento de enemigos, los actos de autoridad ejercidos por un funcionario público, etc.”.

Lo mencionado evidencia la necesidad de precisar si lo sustentado soporta la permanencia de la imprevisibilidad en las causales de exoneración, o si, por el contrario, esta debe ser excluida por su falta de vigencia, ante lo cual considero que debe velarse por su permanencia. Por un lado, al ser parte de la estructura lógica la valoración del comportamiento humano que compromete o libera de responsabilidad; por lo menos así se ha entendido al mencionar que la obligación de prever, en la diligencia propia de la culpa, no puede concurrir en un mismo supuesto fáctico con la imprevisibilidad, puesto que si el deudor tenía la obligación de prever, por las circunstancias en las que se encontraba, no podría exonerarse de responsabilidad. Y por otro lado, por cuanto la previsión e imprevisión,

38 Tamayo Jaramillo, ob. cit., 43.

39 Paillet, M., La responsabilidad administrativa, Bogotá, Universidad Externado de Colombia, 2003, 95-97.

40 Mazeaud, ob. cit., I 77, I 78.

4 I Ibíd., 34 . 
anticipación o no, presentan la exigencia al deudor de actuar de otro modo basado en el deber que tiene de evitar la causación de daños y prevenir alterar con ello las condiciones de existencia de la víctima.

\section{Conclusión}

En la actualidad el derecho de daños se ha orientado a dar relevancia a la exigencia de una conducta encaminada a prevenir la generación de daños o a mitigar los que se ocasionen con el despliegue del comportamiento humano. Deviene de ello la importancia de identificar el papel de la previsión en la responsabilidad y la incidencia de su opuesto, la imprevisión, como una forma de anticipación objetiva que no es extraña en la reparación; por el contrario, se trata de conceptos que están en la base de los juicios de imputación de la responsabilidad por la causación del daño.

Del tráfico jurídico se han desprendido situaciones que llevan a poner en el eje central del debate la evitación de la causación de daños. Con diferentes enfoques, la fuerza de la carga de la prevención ha venido tomando un papel protagónico, del cual se han derivado posturas tendientes a justificar la existencia de deberes de anticipación probable; si bien esta es, al parecer, la nueva vía, a la estructura del reproche frente al evento dañino no son ajenas las condiciones de mitigación, evitabilidad, anticipación y prevención, tal y como se señaló al tratar de las características propias de la categorización de una conducta diligente o no.

Si bien el concepto de previsibilidad ha sido criticado, su contenido determinante en los elementos de la responsabilidad continúa exponiéndolo como factor importante. Así, al tratarse de un concepto que ha venido mutando con el devenir de la implementación de los diferentes juicios, merece la pena reflexionar sobre la posibilidad de considerar a la previsión como un factor netamente objetivo que sirva como un elemento de verificación que otorgue certezas frente a las variables inherentes a las valoraciones de la conducta humana, esto a través de una anticipación medible y comprobable.

\section{Referencias}

\section{Doctrina}

Alessandri Rodríguez, A. y Somarriva Undurraga, M., Curso de derecho civil. Basado en las explicaciones de los profesores de la Universidad de Chile, redactado y puesto al día por A. Vodanovic H., t. I, Santiago de Chile, Nascimento, 1939.

Betti, E., Teoría general del negocio jurídico, $2 .^{\mathrm{a}}$ ed., trad. y concordancias con el derecho español por A. Martín Pérez, Madrid, Revista de Derecho Privado, I959.

Bianca, C. M.; Alpa, G.; Corsaro, L.; Fernández Cruz, G.; Franzoni, M. P.; Monateri, G.; Salvi, C. y Schlesinger, P., Estudios sobre la responsabilidad civil, trad. y ed. L. L. León, Lima, Ara, 200 I. 
Bustamante Alsina, J., Teoría general de la responsabilidad civil, 9. . ed., Buenos Aires, Abeledo-Perrot, 1997 .

Cariota Ferrara, L., El negocio jurídico, trad., prólogo y notas de M. Albaladejo, Madrid, Aguilar, 1956.

Connu, G., Vocabulaire juridique, Association Henri Capitant, 8. ${ }^{\text {e ed., }} 2000$.

Cortés, E., La culpa contractual en el sistema jurídico latinoamericano, 2. a ed., Bogotá, Universidad Externado de Colombia, 2009.

De Cupis, A., El daño, trad. de la 2. ${ }^{a}$ ed. y estudio preliminar de Á. Martínez Sarrión, Barcelona, Bosch, I975.

Diccionario de Derecho Usual, 4. ${ }^{\text {a }}$ ed., t. iII, Buenos Aires, Omeba, ig62.

Díez Picazo, L., Derecho de daños, Madrid, Civitas, I999.

Henao, J. C., El daño, Bogotá, Universidad Externado de Colombia, I 998.

Hinestrosa, F., Conferencias de obligaciones, Bogotá, Universidad Externado de Colombia, I955.

Lecuyer, H., "El contrato: acto de previsión”, en Revista de Derecho Privado, Universidad Externado de Colombia, n. ${ }^{\circ}$ i 8, 20 го.

Mazeaud, H. y L., Tratado teórico y práctico de la responsabilidad civil delictual y contractual, t. II, vol. II, trad. de la 5. ${ }^{\text {a }}$ ed., L. Alcalá Zamora y Castillo, Buenos Aires, EJEA, I963.

Mosset Iturraspe, J., Responsabilidad por daños, vol. i, "Parte general”, t. I, Buenos Aires, Ediar, I97I.

Paillet, M., La responsabilidad administrativa, Bogotá, Universidad Externado de Colombia, 2003 .

Peirano Facio, J., Responsabilidad extracontractual, Buenos Aires, Depalma, I954.

Sarmiento, M. G., Estudios de responsabilidad civil, 2. a ed., Bogotá, Universidad Externado de Colombia, 2009.

Tamayo Jaramillo, J., Tratado de responsabilidad civil, t. I, 5. reimp., Bogotá, Legis, 20 io.

VIney, G. Tratado de derecho civil. Introducción a la responsabilidad, trad. F. Montoya Mateus, Bogotá, Universidad Externado de Colombia, 2007.

\section{Jurisprudencia}

Corte Constitucional. Sentencia C-roo8 de 20ıо, M.P.: Luis Ernesto Vargas Silva.

Consejo de Estado, Sala de lo Contencioso Administrativo, Sección Tercera. I9 de agosto de 1994; C.P.: Daniel Suárez Hernández, exp. 9.276.

Consejo de Estado, Sala de lo Contencioso Administrativo, Sección Tercera. 26 de marzo de 2008 , exp. I6.530, C.P.: Mauricio Fajardo Gómez.

Corte Suprema de Justicia, Sala de Casación Civil. 27 de febrero 2009, ref. 733 I9-3103002-200I-OO०I3-OI, M.P.: Arturo Solarte Rodríguez.

Consejo de Estado, Sala de lo Contencioso, Administrativo, Sección Tercera. 26 de marzo de 2008, exp.: 6.530, C.P.: Mauricio Fajardo Gómez. 
Consejo de Estado, Sala Contencioso Administrativo, Sección Tercera. i I de septiembre de 2003, exp. I4.78 I, C.P.: Ricardo Hoyos Duque.

Corte Suprema de Justicia. 23 de junio de 2000, exp. 5.475, M.P.: Carlos Ignacio Jaramillo Jaramillo.

Consejo de Estado, Sala Contencioso Administrativo, Sección Tercera. 9 de junio de 2005 , exp. I4.392.

Consejo de Estado, Sala de lo Contencioso Administrativo, Sección Tercera, Subsección A. 9 de febrero de 201 I, exp. 19.462 . 